\title{
Tumor Findings Completion Status
}

National Cancer Institute

\section{Source}

National Cancer Institute. Tumor Findings Completion Status. NCI Thesaurus. Code C119942.

A term used to describe the state or condition of the completeness of the tumor findings data. 